\title{
Qualidade Sanitária e Fisiológica de Sementes de Milho Submetidas a Termoterapia e Condicionamento Fisiológico
}

\author{
Wirton M. Coutinho', Renata Silva-Mann², Maria das Graças G.C. Vieira ${ }^{4}$, \\ Cibele F. Machado ${ }^{4}$ \& José C. Machado 5
}

\begin{abstract}
'Embrapa Algodão, Cx. Postal 174, CEP 58107-720, Campina Grande, PB, Brasil, e-mail: wirton@enpa.embrapa.br; ${ }^{2}$ Departamento de Eng. Agronômica, Universidade Federal de Sergipe, Av. Marechal Rondon s/n, CEP 49100-000, São Cristóvão, SE, Brasil; ${ }^{3}$ Departamento de Agricultura, Universidade Federal de Lavras; ${ }^{4}$ Department of Molecular and Cellular Biology, University of Guelph, Guelph, ON, N1G 2W1, Canadá; ${ }^{5}$ Departamento de Fitopatologia, Universidade Federal de Lavras, Cx. Postal 3037, CEP 37200-000, Lavras, MG, Brasil
\end{abstract}

Autor para correspondência: Wirton M. Coutinho

COUTINHO, W.M., SILVA-MANN, R., VIEIRA, M.G.G.C., MACHADO, C.F. \& MACHADO, J.C. Qualidade sanitária e fisiológica de sementes de milho submetidas a termoterapia e condicionamento fisiológico. Fitopatologia Brasileira 32:458464. 2007.

\begin{abstract}
RESUMO
Atermoterapia é uma medida de controle tradicionalmente utilizada com sucesso para eliminação de patógenos em sementes de espécies hospedeiras. Trata-se, no entanto, de uma medida que provoca alterações fisiológicas e bioquímicas nas sementes em diferentes intensidades, podendo comprometer o desempenho das mesmas nas condições de cultivo. Objetivou-se com este trabalho avaliar a eficácia da termoterapia no controle de alguns fungos associados a sementes de milho e do condicionamento osmótico, após o tratamento térmico, no sentido de reparar danos nas sementes provocados nestas circunstâncias. Os fungos associados às sementes foram avaliados por meio do método de incubação em substrato de papel com congelamento, e a qualidade fisiológica das sementes pelos testes de germinação, primeira contagem, condutividade elétrica, e padrões eletroforéticos das enzimas esterase (EST), malato desidrogenase (MDH) e álcool desidrogenase (ADH). O tratamento térmico utilizado foi por imersão em água aquecida a $60^{\circ} \mathrm{C}$ por 5,10 e 20 minutos. Após o tratamento, uma fração das sementes foi submetida ao condicionamento fisiológico em rolo de papel embebido em solução de PEG 6000 a -1,2 MPa. Todos os tratamentos térmicos reduziram ou eliminaram Acremonium strictum das sementes. A incidência de Fusarium verticillioides foi reduzida significativamente pelo tratamento térmico nos períodos de 10 e 20 minutos. À medida que se aumentou o tempo de exposição ao tratamento térmico, houve aumento dos valores de condutividade elétrica e redução significativa da primeira contagem e germinação das sementes. $\mathrm{O}$ tratamento térmico durante 20 minutos alterou os padrões eletroforéticos das enzimas esterase e malato desidrogenase. $\mathrm{O}$ condicionamento fisiológico das sementes não foi capaz de reverter os danos causados pela termoterapia.
\end{abstract}

Palavras-chave adicionais: Zea mays, Acremonium strictum, Fusarium verticillioides, tratamento de sementes, priming.

\begin{abstract}
Health and physiological quality of maize seeds submitted to thermotherapy and physiological preconditioning

Thermotherapy has been used for eliminating fungi on seeds. However, physiological and biochemical alterations, which may occur on seeds following this treatment, have not been thoroughly investigated. In this work, the efficacy of heat treatment (hot water) followed by osmopriming, in the control of fungi associated with maize seeds and its effects on physiological seed quality, was evaluated. The fungi associated with the seeds were detected by the deep-freezing blotter method, and physiological quality was determined by germination, first-germination counting and electric conductivity tests in addition to determination of eletrophoretic patterns of the enzymes: esterase (EST), malate dehidrogenase (MDH) and alcohol dehidrogenase (ADH). The heat treatment used was hot water at $60^{\circ} \mathrm{C}$ for 5,10 and 20 minutes. After treatment, a fraction of the seeds was submitted to osmopriming on roll paper soaked in PEG 6000 solution at $-1.2 \mathrm{MPa}$. All heat treatments reduced or eliminated Acremonium strictum on maize seeds. Heat treatments for 10 and 20 minutes reduced significantly the percentage of Fusarium verticillioides. Increasing period of heat treatment raised the values of conductivity and reduced significantly seed germination rate and firstgermination counting. Heat treatment for 20 minutes altered the eletrophoretic pattern of esterase and malate dehidrogenase enzymes. Osmopriming did not reverse damage caused by the heat treatments.
\end{abstract}

Additional keywords: Zea mays, Acremonium strictum, Fusarium verticillioides, seed treatment, priming.

\section{INTRODUÇÃO}

Fungos fitopatogênicos podem associar-se a sementes de milho em todas as etapas de produção. Esta associação é responsável, muitas vezes, pela redução da qualidade fisiológica das sementes, dispersão de patógenos a longas distâncias e transmissão de patógenos da semente à planta. A eliminação ou redução do inóculo infectivo de fungos em sementes, tem sido eficientemente alcançada por tratamentos químicos, biológicos e físicos. Dentre os métodos físicos, a eficácia da termoterapia, que consiste na exposição das sementes à ação do calor em combinação com o tempo 
Qualidade sanitária e fisiológica de sementes de milho...

de tratamento, tem sido demonstrada em vários estudos (Bergman, 1994; Trigo et al., 1998; Machado, 2000).

Embora eficiente no controle de patógenos associados a sementes, a termoterapia pode causar danos à sua qualidade fisiológica, principalmente pelo rompimento das membranas celulares ou desnaturação de proteínas dos tecidos externos, os quais podem ocasionar a perda de metabólitos que podem ser utilizados na germinação e no crescimento da plântula (Machado, 2000). Uma tentativa de melhorar a qualidade fisiológica de sementes, sobretudo daquelas submetidas a condições de estresse, como no caso dos tratamentos térmicos, é o condicionamento fisiológico das sementes (Heydecker et al., 1975); esta técnica é baseada no controle da velocidade de embebição de água pelas sementes em soluções iônicas ou não iônicas, ajustadas a potenciais hídricos que permitam a ocorrência dos processos fisiológicos iniciais, sem atingir umidade suficiente para que ocorra o elongamento celular e, em conseqüência, a protusão da radícula (Bradford, 1986).

Dentre os vários efeitos do condicionamento fisiológico na melhoria da qualidade fisiológica de sementes, estão a restauração da integridade do sistema de membranas, perdida durante o processo de desidratação na maturação das sementes, e o aumento da disponibilidade de metabólitos que podem ser assimilados na germinação e no crescimento da plântula (Knypl \& Khan, 1981). Efeitos indiretos, como aqueles resultantes da redução do tombamento de plantas, causados por fungos de solo em razão da diminuição da quantidade de nutrientes liberados das sementes durante a embebição, foram também observados (Osburn \& Schroth, 1988).

As alterações na fisiologia das sementes estão indiretamente relacionadas com a integridade das membranas celulares, as quais dependem da variedade de enzimas e proteínas estruturais de cada espécie; no entanto, essas variações em nível de membranas nem sempre podem ser avaliadas por testes de germinação e vigor (Vieira, 1996). Uma alternativa seria a utilização de análises de isoenzimas que, por serem mais sensíveis, podem medir a deterioração incipiente através da expressão da atividade de certas enzimas associadas à quebra de reservas ou à biossíntese de tecidos novos. Diversos trabalhos têm sido desenvolvidos no sentido de se estudar as mudanças nas atividades de isoenzimas que ocorrem em sementes em deterioração; normalmente, nesses trabalhos são utilizadas enzimas importantes no processo de respiração celular, como a malato desidrogenase, ou enzimas importantes no metabolismo de ligação nitrogênio e carbono e ponto de regulação, que são potencialmente importantes na germinação de sementes, como a glutamato desidrogenase ou, ainda, enzimas que desempenham tarefas chaves no metabolismo dos lipídios, significativas no desenvolvimento e germinação de sementes, como as esterases e a fosfatase ácida.

Especificamente para o caso de sementes de milho, informações sobre emprego da termoterapia são escassos. É oportuno ressaltar que, para culturas de produção mais extensiva, esse tipo de tratamento de sementes não é comumente recomendável, salvo situações de pequenos volumes, geralmente com finalidade de pesquisa ou para uso em programas de melhoramento em fase inicial (Machado, 2000). Em um dos poucos relatos encontrados na literatura, o uso da termoterapia para sementes de milho mostrouse eficaz no controle de alguns patógenos. Não ficaram evidenciadas as implicações da termoterapia considerando-se alguns fatores que normalmente interferem no desempenho deste tipo de tratamento. (Erdey et al., 1997). Objetivou-se neste trabalho avaliar os efeitos da termoterapia, com e sem posterior condicionamento fisiológico, sobre a qualidade sanitária e fisiológica de sementes de milho.

\section{MATERIAL E MÉTODOS}

Os ensaios foram conduzidos nos Laboratórios de Patologia de Sementes e de Análise de Sementes da Universidade Federal de Lavras (UFLA), no período de 1999 a 2000. Utilizaram-se sementes de milho (Zea mays L.), safra 1998/1999. A viabilidade das sementes foi determinada por meio do teste de germinação (Brasil, 1992), obtendo-se $92 \%$ de germinação. O tratamento térmico empregado foi por imersão em água aquecida à temperatura de $60^{\circ} \mathrm{C}$ por 5,10 e 20 minutos. As sementes foram acondicionadas em sacos de filó, os quais foram dispostos aleatoriamente em banho-maria com água aquecida na temperatura e tempos de tratamento predeterminados. Previamente aos tratamentos térmicos, as sementes foram embebidas em água não aquecida, durante uma hora, para eliminação de bolsões de ar entre os tecidos mortos superficiais e facilitar a condução do calor nos tecidos das sementes.

Após os tratamentos térmicos, as sementes foram postas para secar sobre papel toalha a temperatura ambiente, e uma fração delas submetida ao condicionamento fisiológico (priming) em rolo de papel embebido em solução de polietilenoglicol (PEG) $6000 \mathrm{a}-1,2 \mathrm{MPa}$, durante três dias à temperatura de $25^{\circ} \mathrm{C}$ em câmara do tipo BOD. O cálculo da solução de PEG 6000 foi realizado utilizando-se a equação desenvolvida por Michel \& Kaufmann (1973).

A qualidade sanitária das sementes foi avaliada pelo teste de incubação em substrato de papel com congelamento, enquanto a qualidade fisiológica pelos testes de germinação, primeira contagem e condutividade elétrica. Além desses testes, a ocorrência de alterações fisiológicas e bioquímicas das sementes submetidas à termoterapia, com ou sem posterior condicionamento fisiológico, foi determinada pelos padrões eletroforéticos das enzimas esterase, malato desidrogenase e álcool desidrogenase.

$\mathrm{O}$ teste de sanidade foi realizado pelo método de incubação em substrato de papel com congelamento, conforme as Regras para Análise de Sementes (Brasil, 1992). Utilizaram-se 200 sementes (oito repetições de 25 sementes) para cada tratamento. As sementes foram distribuídas em placas de Petri de $15 \mathrm{~cm}$ de diâmetro, contendo três folhas de papel de filtro $\left(80 \mathrm{~g} / \mathrm{m}^{2}\right)$ previamente 
esterilizadas e umedecidas com água destilada e autoclavada. Inicialmente, as placas foram incubadas durante 24 horas à temperatura de $20^{\circ} \mathrm{C} \pm 2{ }^{\circ} \mathrm{C}$, depois a $-20^{\circ} \mathrm{C}$ por 24 horas e, em seguida, incubadas por cinco dias em câmara de incubação com temperatura de $20^{\circ} \mathrm{C} \pm 2^{\circ} \mathrm{C}$ e fotoperíodo de 12 horas (luz com comprimento de onda próximo ao ultravioleta). As avaliações quantitativa e qualitativa dos fungos associados às sementes foram realizadas após oito dias de incubação, examinando-se, individualmente, as sementes ao microscópio estereoscópico. Em alguns casos, a identificação foi confirmada pela visualização das estruturas morfológicas dos fungos ao microscópio óptico.

Para o teste de germinação foram utilizadas 200 sementes (quatro repetições de 50 sementes) para cada tratamento, distribuídas em rolos de papel germitest previamente esterilizados e colocadas para germinar em câmara de germinação com temperatura constante de $25^{\circ} \mathrm{C}$. $\mathrm{O}$ volume de água destilada utilizada para embebição foi equivalente a 2,5 vezes o peso do substrato. As contagens foram realizadas aos quatro e sete dias após a semeadura; as avaliações foram realizadas de acordo com os critérios estabelecidos pelas Regras para Análise de Sementes (Brasil, 1992). A primeira contagem do teste de germinação foi realizada em conjunto com o teste de germinação, avaliandose o número de plântulas normais determinado no quarto dia após a semeadura.

Para a realização do teste de condutividade elétrica foram utilizadas 100 sementes (quatro repetições de 25 sementes), as quais foram previamente pesadas com precisão de centigramas e acondicionadas em copos plásticos descartáveis $(200 \mathrm{~mL})$ contendo $75 \mathrm{~mL}$ de água deionizada, sendo mantidos em uma câmara com temperatura de $20^{\circ} \mathrm{C}$ por 24 horas (AOSA, 1983); após este período, retiraramse as amostras e procedeu-se à leitura da condutividade elétrica da solução de embebição das sementes de milho em condutivímetro Digimed, modelo CD 21. Os resultados foram expressos em $\mu \mathrm{S} / \mathrm{cm} / \mathrm{g}$.

Para a análise de isoenzimas foram empregados microtubos contendo $100 \mathrm{mg}$ de sementes trituradas e $200 \mu \mathrm{L}$ de tampão de extração (Tris- $\mathrm{HCl} 0,2 \mathrm{M}, \mathrm{pH}$ 8,0, mercaptoetanol $0,1 \%$, polivinilpirrolidone - PVP $40 \quad 0,4 \%$, polietilenoglicol (PEG) $6000 \quad 0,4 \%$, ácido etilenodiaminotetracético (EDTA) $1 \mathrm{mM}$ ). A mistura foi mantida a $4^{\circ} \mathrm{C}$ por 24 horas e, posteriormente, centrifugada a $16,000 \times \mathrm{g}$, por 30 minutos, a $4^{\circ} \mathrm{C}$. Para avaliação dos perfis eletroforéticos, aplicaram-se $30 \mu \mathrm{L}$ de extrato protéico de cada amostra nas cavidades dos géis de poliacrilamida a 4,5\% e 7,5\%. As isoenzimas foram separadas por eletroforese por aproximadamente 3 horas a $4^{\circ} \mathrm{C}$, a $150 \mathrm{~V}$, e reveladas para os sistemas esterase (EST), malato desidrogenase (MDH) e álcool desidrogenase (ADH) (Alfenas et al., 1991).

O delineamento experimental utilizado nos testes de qualidade fisiológica (germinação, primeira contagem e condutividade elétrica) foi o inteiramente casualizado, enquanto na avaliação da sanidade adotou-se o de blocos ao acaso, ambos em esquema fatorial $2 \times 4$, sendo sementes com ou sem posterior condicionamento osmótico após tratamento térmico em quatro tempos de exposição a $60^{\circ} \mathrm{C}(0,5,10$ e 20 minutos). A análise estatística foi realizada por meio do procedimento ANOVA, do software estatístico SAS system ${ }^{\circledR}$ versão 8.0 (SAS Institute Inc. Cary, NC, USA). Avaliaramse os efeitos de condicionamento osmótico, tempos de exposição a $60^{\circ} \mathrm{C}$ e interação entre condicionamento e tempos. Análises de regressão foram realizadas quando se verificaram efeitos significativos $(\mathrm{P} \leq 0,05)$ de tempos de exposição a $60^{\circ} \mathrm{C}$ ou da interação condicionamento osmótico $\times$ tempos de exposição.

\section{RESULTADOS E DISCUSSÃO}

Os resultados referentes à ocorrência (porcentagem de sementes com fungos) de Fusarium verticillioides (Sacc.) Nirenberg e Acremonium strictum W. Gams em sementes de milho submetidas à termoterapia $\left(60^{\circ} \mathrm{C}\right)$ por diferentes períodos de tempo, com ou sem posterior condicionamento osmótico, são apresentados nas Figuras 1 e 2.

Para $F$. verticillioides, foram observados efeitos significativos $(\mathrm{P} \leq 0,05)$ em relação à duração do tratamento térmico, sendo ajustada uma equação média de regressão linear aos dados de ocorrência do fungo em sementes condicionadas e não condicionadas osmoticamente após o tratamento (Figura 1). À medida que se aumentou o tempo do tratamento térmico a $60^{\circ} \mathrm{C}$, constatou-se redução significativa da ocorrência do fungo, principalmente nos tempos de 10 e 20 minutos.

Na avaliação de $A$. strictum não foi realizada análise de variância dos dados, em razão dos mesmos não apresentarem normalidade e homogeneidade de variância (Figura 2). Entretanto, nas sementes submetidas ao condicionamento osmótico constatou-se redução da ocorrência do fungo no tratamento térmico de cinco minutos e a sua eliminação nos tempos de tratamento de 10 e 20 minutos; nas sementes

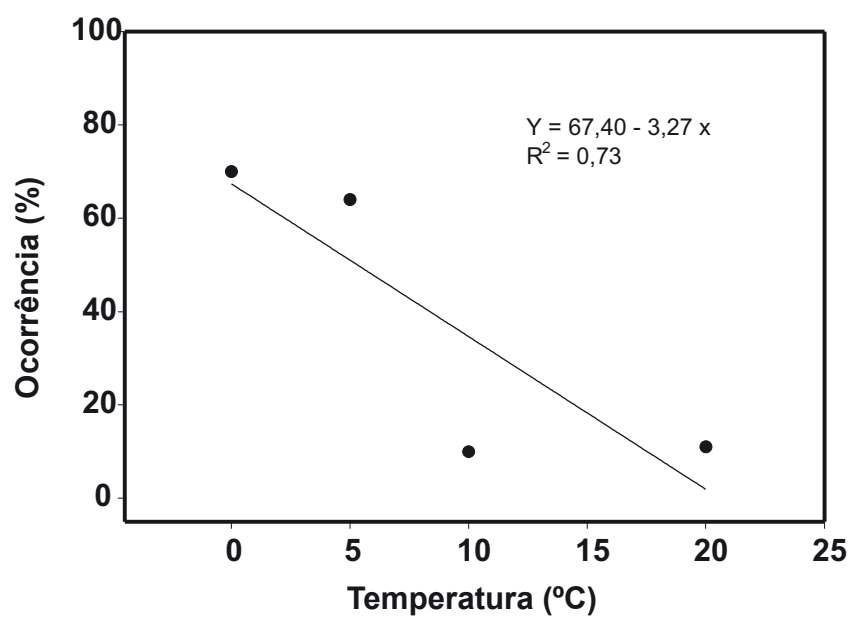

FIG. 1 - Ocorrência de Fusarium verticillioides em sementes de milho submetidas à termoterapia $\left(60^{\circ} \mathrm{C}\right)$, durante diferentes tempos de tratamento, com ou sem posterior condicionamento fisiológico. 


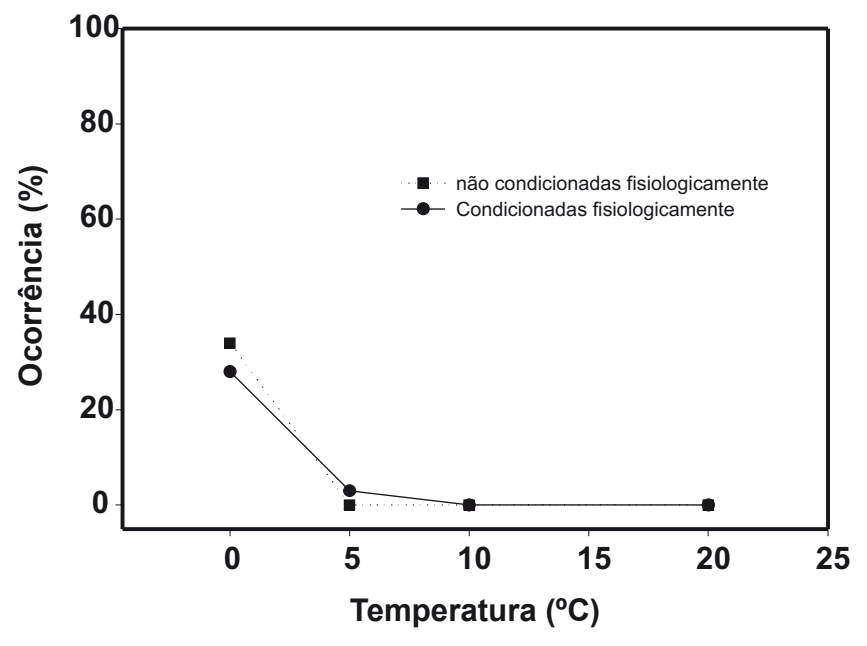

FIG. 2 - Ocorrência de Acremonium strictum em sementes de milho submetidas à termoterapia $\left(60^{\circ} \mathrm{C}\right)$, durante diferentes tempos de tratamento, com ou sem posterior condicionamento fisiológico.

não condicionadas, todos os tempos de tratamento térmico testados eliminaram os fungos das sementes.

Os resultados referentes aos testes de germinação, primeira contagem e condutividade elétrica de sementes de milho submetidas aos tratamentos testados são apresentados nas Figuras 3, 4 e 5. Em todos os parâmetros avaliados foram observados efeitos significativos $(\mathrm{P} \leq 0,05)$ de tempos de tratamento térmico e da interação condicionamento osmótico $\times$ temperatura.

Tanto na avaliação de germinação como na de primeira contagem (Figuras 3 e 4), à medida que se aumentou o tempo de tratamento térmico diminuiu a porcentagem de plântulas normais, culminando com a perda total da capacidade germinativa das sementes no tempo de 20 minutos. Constatou-se, entretanto, melhor desempenho das sementes submetidas ao condicionamento osmótico, principalmente no tempo de 10 minutos de termoterapia, embora o condicionamento osmótico das sementes não tenha sido eficiente para reverter os danos causados pela termoterapia a $60^{\circ} \mathrm{C}$ nos tempos estudados.

Pelo teste de condutividade elétrica, que avalia a permeabilidade seletiva de membranas celulares, verifiou-se o aumento da lixiviação de exsudatos das sementes com o aumento do período de duração do tratamento térmico seguido ou não de condicionamento osmótico (Figura 5). Nesse sentido, a redução da qualidade fisiológica das sementes, resultante do aumento do tempo de tratamento, observada principalmente nos tempos de 10 e 20 minutos, pode estar relacionada à perda da integridade do sistema de membranas das sementes, resultando na lixiviação de metabólitos essenciais aos processos de germinação e crescimento. Assim, como verificado nos testes de germinação e primeira contagem, o condicionamento osmótico não foi eficiente na reversão dos danos causados à qualidade fisiológica das sementes nos tempos de tratamento testados.

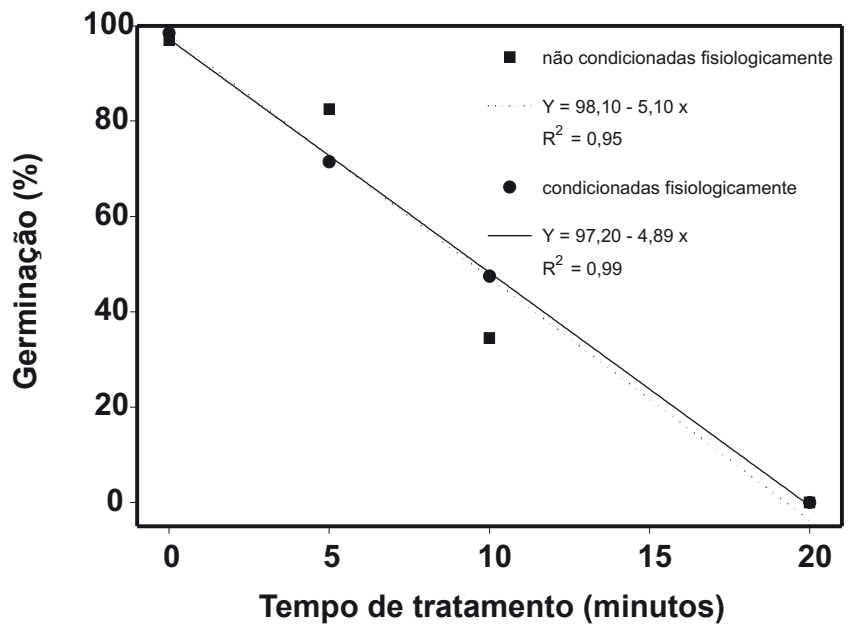

FIG. 3 - Germinação de sementes de milho submetidas à termoterapia $\left(60^{\circ} \mathrm{C}\right)$, durante diferentes tempos de tratamento, com ou sem posterior condicionamento fisiológico.

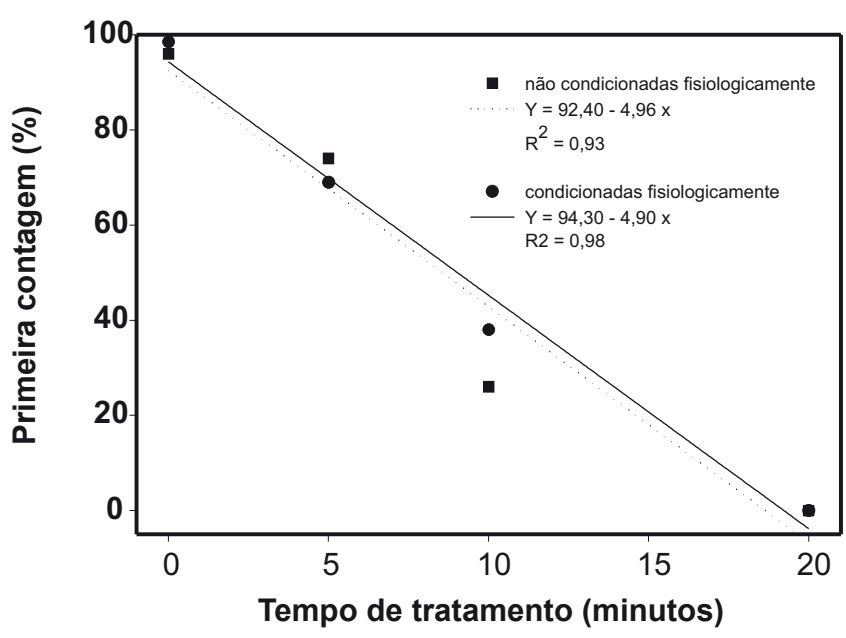

FIG. 4 - Primeira contagem de germinação de sementes de milho submetidas à termoterapia $\left(60^{\circ} \mathrm{C}\right)$, durante diferentes tempos de tratamento, com ou sem posterior condicionamento fisiológico.

Os tempos de tratamento térmico de 10 e 20 minutos, os quais foram os mais eficazes no controle dos fungos, principalmente de $F$. verticillioides, afetaram adversamente a qualidade fisiológica das sementes, colocando o lote em questão fora dos padrões de certificação e comercialização, conforme normas da Comissão de Sementes e Mudas de Minas Gerais (CESM - MG). A termoterapia de sementes, visando ao controle de patógenos, baseia-se no diferencial dos pontos térmicos letais de sementes e patógenos, sendo que o sucesso deste método será maior sempre que esses pontos estiverem bem distanciados um do outro (Machado, 2000). Neste estudo, verificou-se que os pontos térmicos letais de sementes de milho e $F$. verticillioides estão muito próximos, inviabilizando o sucesso da técnica no controle 


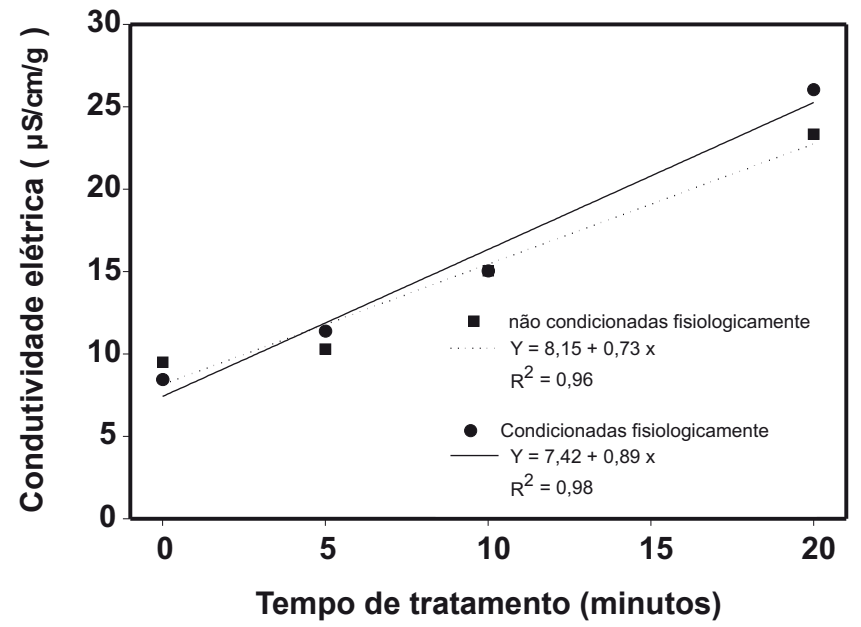

FIG. 5 - Condutividade elétrica de sementes de milho submetidas à termoterapia $\left(60^{\circ} \mathrm{C}\right)$, durante diferentes tempos de tratamento, com ou sem posterior condicionamento fisiológico.

do patógeno; entretanto, para $A$. strictum, os pontos térmicos letais deste e de sementes de milho estão mais distanciados, o que permitiu controle maior do fungo no tempo de tratamento de cinco minutos com menores danos causados à qualidade fisiológica das sementes.

Pelos padrões isoenzimáticos de esterase, verificouse uma redução acentuada da atividade desta enzima em sementes expostas ao calor por 20 minutos, com e sem posterior condicionamento osmótico (Figura 6). A enzima esterase participa de reações de hidrólise de ésteres e, portanto, atua diretamente no metabolismo dos lipídios. Vale ressaltar que as sementes submetidas à termoterapia por 20 minutos perderam sua capacidade germinativa (Figura 3 ), sendo este evento a conseqüência ou o efeito final da deterioração das sementes (Delouche, 2002). Em adição, estas sementes apresentaram valores relativamente elevados no teste de condutividade elétrica (Figura 5), implicando numa maior desestruturação das membranas celulares. Nesse sentido, a diminuição da atividade das isoenzimas de esterase, verificada pela redução da intensidade das bandas, pode estar relacionada com a perda da integridade do sistema de membranas (Givelberg et al., 1984; Machado, 2000), com a auto-oxidação de ácidos graxos (Flood \& Sinclair, 1981), com a liberação de lipídios (Baker, 1962), ou até mesmo com a desnaturação da enzima (Baker, 1962), eventos estes decorrentes da exposição das sementes a temperaturas elevadas. Estes resultados estão de acordo com aqueles obtidos por Padilha et al. (2001) com sementes de milho, em que a intensidade das bandas de esterase foi reduzida sob condições drásticas de estresse.

Da mesma forma, a atividade de algumas isoenzimas de malato desidrogenase foi reduzida em sementes de milho submetidas à termoterapia por 20 minutos, com e sem posterior condicionamento osmótico (Figura 6). A enzima malato desidrogenase catalisa a última reação do ciclo de Krebs, oxidando malato a oxaloacetato e produzindo
NADH (Siedow \& Day, 2000). A redução da atividade de isoenzimas de malato desidrogenase, indicando a redução da capacidade respiratória das sementes, é, possivelmente, resultante de danos nas membranas mitocondriais causados pela exposição das sementes à temperatura elevada (AbuShakra \& Ching, 1967), visto que, no presente caso, estes danos foram evidenciados pelo período prolongado do tratamento. A queda do desempenho germinativo das sementes com o aumento do período de tratamento térmico verificada neste trabalho pode ser atribuída, em grande parte, aos danos ocasionados às membranas mitocondriais e conseqüente redução da taxa respiratória, pois a energia necessária para a germinação das sementes é fornecida pelas mitocôndrias dos eixos embrionários (Salinas et al., 1998). Em um outro estudo, a redução da atividade de malato desidrogenase também foi verificada em sementes de feijão envelhecidas artificialmente (Santos et al., 2004).

Em contraste, o estresse provocado pelo tratamento térmico de 20 minutos em sementes de milho não foi suficiente para diminuir a atividade da enzima álcool desidrogenase, sendo esta a mais estável em relação ao período de tratamento. A enzima álcool desidrogenase atua no metabolismo anaeróbico, reduzindo acetaldeído a etanol e oxidando NADH a NAD ${ }^{+}$(Bray et al., 2000). Embora esta enzima tenha apresentado atividade em sementes de milho em todos os tratamentos testados, com padrões eletroforéticos semelhantes, a fermentação alcoólica parece ter sido a principal rota de produção

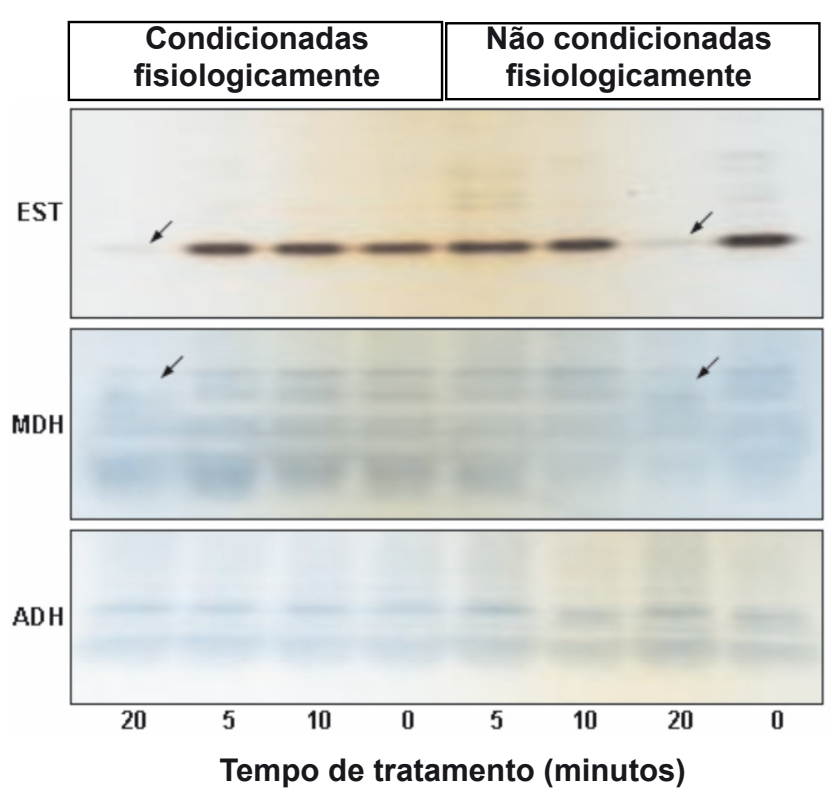

FIG. 6 - Perfis eletroforéticos das enzimas esterase (EST), malato desidrogenase (MDH) e álcool desidrogenase (ADH) em sementes de milho submetidas à termoterapia $\left(60^{\circ} \mathrm{C}\right)$, durante diferentes tempos de tratamento, com ou sem posterior condicionamento fisiológico. 
de ATP nas sementes submetidas à termoterapia por 20 minutos, uma vez que a atividade respiratória aeróbica foi afetada nessas sementes, conforme indicado pelos perfis isoenzimáticos de malato desidrogenase relatados anteriormente (Figura 6).

Diante desses resultados, percebe-se que a termoterapia de sementes de milho em água a $60^{\circ} \mathrm{C}$, por períodos de até 20 minutos, foi eficaz no controle dos fungos Fusarium verticillioides e Acremonium strictum, porém, afetou adversamente a qualidade das sementes, ocasionando alterações fisiológicas e/ou enzimáticas, as quais também foram influenciadas pelo tempo de exposição das sementes ao calor.

O condicionamento osmótico de sementes é uma técnica utilizada com o objetivo de melhorar o desempenho das mesmas, e um dos fatores contribuintes para os seus benefícios é a ativação dos mecanismos de reparo de danos no sistema de membranas (Fujikura \& Karssen, 1992; Powell, 1998). Os danos causados pela termoterapia em sementes de milho, mais provavelmente no sistema de membranas, foram irreversíveis, uma vez que o condicionamento fisiológico não foi capaz de restabelecer a qualidade inicial das sementes. Como alternativa ao tratamento térmico via imersão em água aquecida estima-se que o uso do vapor arejado pode ser eficaz para o controle dos fungos em foco associados às sementes de milho.

\section{AGRADECIMENTOS}

Ao Conselho de Desenvolvimento Científico e Tecnológico - CNPq à Fundação de Apoio à Pesquisa do Estado de Minas Gerais - FAPEMIG pela concessão de bolsa de estudo e financiamento do projeto.

\section{REFERÊNCIAS BIBLIOGRÁFICAS}

ABU-SHAKRA, S.S. \& CHING, T.M. Mitochondrial activity in germinating new and old soybean seeds. Crop Science 7:115-118. 1967.

ALFENAS, A.C., PETERS, I., BRUNE, W. \& PASSADOR, G.C. Eletroforese de proteínas e isoenzimas de fungos de essências florestais. Viçosa MG. Editora UFV. 1991.

AOSA - ASSOCIATION OF OFFICIAL SEED ANALYSTS. Seed vigor testing handbook. East Lansing. 1983. (Contribution, 32)

BAKER, K.F. Principles of heat treatment of soil and planting material. Journal of the Australian Institute of Agriculture Science 28:118-126. 1962.

BERGMAN, S. Hot treatment of seed-borne fungi on cereals. Seed Pathology and Microbiology 5:20-21. 1994.

BRADFORD, K.J. Manipulation of seed water relations via osmotic priming to improve germination under stress conditions.
HortScience 21:1105-1112. 1986.

BRASIL. Ministério da Agricultura e Reforma Agrária. Regras para análise de sementes. Brasília DF. SNAD/DNDV/CLAV. 1992.

BRAY, E.A., BAILEY-SERRES, J. \& WERETILNYK, E. Responses to abiotic stresses. In: Buchanan, B.B., Gruissem, W. \& Jones, R.L. (Eds.) Biochemistry and Molecular Biology of Plants. Rockville MD. American Society of Plant Physiologists. 2000. pp. 1158-1203.

DELOUCHE, J.C. Deterioração de sementes. SEED News 6: 2431. 2002.

ERDEY, D.P., MYCOCK, D.J. \& BERJAK, P. The elimination of Fusarium moniliforme (Sheldon) infection in maize caryopses by hot water treatment. Seed Science and Technology 25:485-501. 1997.

FLOOD, R.G. \& SINCLAIR, A. Fatty acid analysis of aged permeable and impermeable seeds of Trifolium subterranum (subterranean clover). Seed Science and Technology 9:475-477. 1981.

FUJIKURA, Y. \& KARSSEN, C.M. Effects of controlled deterioration and osmopriming on protein synthesis of cauliflower seeds during early germination. Seed Science Research 2:23-31. 1992.

GIVELBERG, A., HOROWITZ, M. \& POLJAKOFF-MAYBER, A. Solute leakage from Solanum nigrum L. seeds exposed to high temperatures during imbibition. Journal of Experimental Botany 35:1754-1763. 1984.

HEYDECKER, W., HIGGINS, J. \& TURNER, Y.J. Invigoration of seeds? Seed Science and Technology 3:881-888. 1975.

KNYPL, J.S. \& KHAN, A.A. Osmo-conditioning of soybean seeds to improve performance at suboptimal temperatures. Agronomy Journal 73:112-116. 1981.

MACHADO, J.C. Tratamento de sementes no controle de doenças. Lavras MG. Editora UFLA. 2000.

MICHEL, B.E. \& KAUFMANN, M.R. The osmotic potential of polyethylene glycol 6000. Plant Physiology 51:914-916. 1973.

OSBURN, R.M. \& SCHROTH, M.N. Effect of osmopriming sugar beet seed on exudation and subsequent damping-off caused by Pythium ultimum. Phytopathology 78:1246-1250. 1988.

PADILHA, L., VIEIRA, M.G.G.C., VON PINHO, E.V.R. \& CARVALHO, M.L.M. Relação entre o teste de deterioração controlada e o desempenho de sementes de milho em diferentes condições de estresse. Revista Brasileira de Sementes 23:198-204. 2001.

POWELL, A.A. Seed improvement by selection and invigoration. Scientia Agricola 55:126-133. 1998.

SALINAS, A.R., SANTOS, D.S.B., VILLELA, F.A., SANTOS FILHO, B.G., SOARES, L.A.S. \& OLIVEIRA, M.F. Fisiologia da deterioração em sementes de soja durante o armazenamento. Revista Científica Rural 3:106-118. 1998.

SANTOS, C.M.R., MENEZES, N.L. \& VILLELA, F.A. Alterações fisiológicas e bioquímicas em sementes de feijão envelhecidas artificialmente. Revista Brasileira de Sementes 26:110-119. 2004.

SIEDOW, J.N. \& DAY, D.A. Respiration and photorespiration. In: Buchanan, B.B., Gruissem, W. \& Jones, R.L. (Eds.) Biochemistry and Molecular Biology of Plants. Rockville MD. American Society 
of Plant Physiologists. 2000. pp. 676-728.

TRIGO, M.F.O., PIEROBOM, C.R., NEDEL, J.L. \& TRIGO, L.F.N. Tratamento térmico em sementes de cenoura. Pesquisa Agropecuária Brasileira 33:357-361. 1998.
VIEIRA, M.G.G.C. Utilização de marcadores moleculares no monitoramento da qualidade sanitária e nível de deterioração de sementes de algodoeiro. Tese de Doutorado. Lavras MG. Universidade Federal de Lavras. 1996.

Recebido 23 Julho 2007 - Aceito 20 Dezembro 2007 - FB 7077 